\title{
Influence of microbial complexes based on microorganisms' polyfunctional strains on the grapes' rootstock rhizogenesis stages passage
}

\author{
Viacheslav Ivanchenko, Anton Zotikov", Oleg Zameta, Sergey Mikhailov, and Dmitry \\ Potanin \\ Agrotechnological Academy CFU named after V.I. Vernadsky, 295492 Simferopol, Agrarnoye, \\ Russian Federation
}

\begin{abstract}
The article presents data on the complex influence study of new microbial preparations Diazophyte, Phosphoenterin, Biopolicide, Aurill and Azotobacterin on biometric indicators of growth and development of grapes rootstock at separate rhizogenesis stages. Standard cuttings of the Berlandieri x Riparia Kober 5 BB rootstock grape variety were used as objects of the four-year study. For the first time, the optimal breeding range of the studied microbial complexes (MPC-1 and MPC-2 in dilution 1:10) was determined; with it, stable efficiency of root formation stimulation of subpar grape variety Berlandieri x Riparia Kober 5BB cuttings was observed. In turn, this is the basis for future studies aimed at finding the optimal concentration in this range. By its effectiveness, the use of these microbial complexes approaches the action of the traditional chemical stimulant Heteroauxin at a concentration of $0.02 \%$.
\end{abstract}

\section{Introduction}

Today, the actual nursery farming problem still is the development of ways to increase rooting of grape cuttings. In this regard, various methods of root formation process activation are used in the production of high-quality planting material, based on mechanical, physical or chemical impact [1]. Each of these methods has its advantages and disadvantages, which in turn is the basis for finding better stimulants. In the last decade, a lot of attention has been paid to synthetic growth stimulants. However, with chemical plant growth regulators, there is a real risk of undesirable effects, both for the environment and for the plants themselves. In this regard, preference should be given to less harmful substances in concentrations with a low safety threshold and within the reaction norm caused by the plant genotype and only in critical periods for them.

The development of agricultural microbiology contributed to significant practical results. The influence of microorganisms on the soil has been studied; the role of symbiotic agrobacteria in the biological method of combating plant diseases and as a source of biologically active substances $[2,3,4]$ was substantiated. It was proven that associative microorganisms have a complex of useful agronomic properties that contribute to providing

* Corresponding author: urjevich@list.ru 
plants with elements of mineral nutrition and stimulate their growth $[5,6,7]$. The use of a microbial preparations complex enhances the influence of useful strains on the production process in plants, provides a higher and more stable increase in years compared to each biopreparation separately. Only active strains of these bacteria provide plants with nitrogen, inactive - inhibit the host plant [8]. There are positive results on the use of biopreparations in fruit nursery [9-11], research in this area is being carried out on industrial fruiting vineyards $[12,13]$. The search for microbial preparations on the basis of microorganisms capable of forming different types of symbioses is being investigated; their influence on the growth and development of grape seedlings in ground nursery gardens' conditions is studied [14-17]. Thus, in the foreseeable future there will be a focus on creating effective preparations based on microbial synthesis, which in turn will contribute to the expansion of their application and increase in their use.

One of the new directions in stimulation is the use of symbiotic microorganisms that have a polyfunctional effect. FSBSI "Research Institute of Crimean Agriculture" created a number of biopreparations, such as Diazophyte (based on Rhizobium (Agrobacterium) radiobacter 204 strain) [12], Phosphoenterin (Enterobacter nimipressuralis32-3 strain) [8], Biopolicide (Paenibacillus polymyxastrain) [13], Aurill ( Bacillus subtilis 01-1 strain) [6, 18] and Azotobacterin (Azotobacter vinelandii 10702 strain), which are able to increase resistance to biotic and abiotic stressors and are stimulants of plants' growth and development $[1,14,16,19,20]$. It is proved that associative microorganisms have a complex of useful agronomic properties that contribute to plants' provision with elements of mineral nutrition, stimulate their growth, increase adaptive potential to stress $[3,7]$.

Earlier studies showed that the polyfunctional complex of biopreparations enhances the beneficial strains' influence on the production process in plants, which provides an increase in crop yield and product quality. Moreover, the use of a microbial preparations' complex contributed to a higher increase than each biopreparation separately [2, 5, 6, 9-12, 17].

The purpose of our work was to study the influence degree of microbial complexes consisting of polyfunctional biopreparations on biometric indicators of roots' growth and development of Berlandieri x Riparia Kober 5BB grape variety rootstock at separate rhizogenesis stages. For this purpose, we solved the problems of determining the optimal dilution range of the studied microbial complexes in which there is the most stable root formation and efficiency comparison of investigated microbial complexes with a traditional chemical stimulant.

\section{Materials and Methods}

Two microbial preparation complexes (MPC) were used in the study. The MPC-1 consisted of the preparations Diazophyte, Phosphoenterin, and Biopolicide. The MPC-2 consisted of Phosphoenterin, Biopolicide, Aurill, and Azotobacterin. Basic solutions of these microbial complexes were obtained by mixing these preparations in a proportion of $1: 1$. The experimental scheme involved treatment with both basic solutions (without water dilution) and their water slurries in $1: 10$ and $1: 100$ dilution. The traditional root stimulant Heteroauxin at a concentration of $0.02 \%$ was chosen as the benchmark. Standard cuttings of the grape rootstock recognized variety Berlandieri x Riparia Kober 5 BB were used as objects of the study.

The research was conducted in March-April 2017-2020 at the Department of Fruit and Vegetable Growing and Viticulture of the Agrotechnological Academy $\left(45^{\circ} 01^{\prime} 60^{\prime \prime}\right.$ n.lat. $34^{\circ} 05^{\prime} 85^{\prime \prime}$ e.lon.) "CFU named after V.I. Vernadsky", located in the Foothill viticultural zone of the Republic of Crimea.

The rootstock vine was harvested in the 3rd decade of February. After harvesting, it was cut into standard cuttings [21] and their blinding. Before cutting, its quality was assessed. 
Quality assessment included traits such as appearance, internodes' length, carbohydrate content, moisture content, degree of aging. After that, the cuttings were placed on compensating soaking for 48 hours by complete immersing of the cuttings into a container of water (water temperature $18^{\circ} \mathrm{C}$ ). Treatment of cuttings was carried out by both basic solutions and aqueous suspension of microbial preparations complexes MPC -1 and MPC - 2 in 1:10 and 1:100 dilution and was done by immersion of basal ends in solutions for 3 minutes. The standard was the traditional root stimulant Heteroauxin at a concentration of $0.02 \%$. Treatment of cuttings with a Heteroauxin solution (by immersing the basal ends into the solution for 20 hours). The control option was cuttings without treatment with stimulants (Table 1).

Table 1. Experiment scheme.

\begin{tabular}{|c|l|}
\hline It.No. & \multicolumn{1}{c|}{$\begin{array}{c}\text { Name of root stimulant, } \\
\text { concentration of working solution }\end{array}$} \\
\hline Option 1 & Control (no treatment) \\
\hline Option 2 & Treatment of basal part with 0.02\% Heteroauxin solution \\
\hline Option 3 & $\begin{array}{l}\text { Treatment of the basal part of MPC-1 with a base solution } \\
\text { (no water dilution) }\end{array}$ \\
\hline Option 4 & Treatment of the basal part of MPC-1 in 1:10 dilution \\
\hline Option 5 & Treatment of basal part of MPC-1 in 1:100 dilution \\
\hline Option 6 & $\begin{array}{l}\text { Treatment of the basal part of MPC-2 with a base solution } \\
\text { (no water dilution) }\end{array}$ \\
\hline Option 7 & Treatment of the basal part of MPC-2 in 1:10 dilution \\
\hline Option 8 & Treatment of the basal part of MPC-2 in 1:100 dilution \\
\hline
\end{tabular}

The cuttings were connected in bundles ( 30 cuttings in three times repetition) according to the experimental scheme and set to a temperature-controlled chamber $\left(22^{\circ} \mathrm{C}\right)$ in a $5 \mathrm{~cm}$ layer of water with no lighting. The duration of the experiment - 50 days. Every 10 days, records were carried out for: the number of cuttings with root base; the number of cuttings with roots formed at the basal ends; cuttings with 3 or more roots.

The obtained data was processed using statistical methods in Micrsoft Excel. Mean values $(M)$, standard mean errors $(M \pm m)$ and coefficients of variation $(C v)$ were calculated. Using the method of dispersion analysis $(A N O V A)$, we determined the significance of differences between the mean values (per the $\mathrm{NSR}_{05}$ criterion); the difference in values at $\mathrm{p}$ $\leq 0.05$ was considered statistically significant. The two-factor dispersion analysis determined the influence share of both individual factors (conditions of the year, stimulants and their concentrations) and their interaction. When determining the impact share of the year's conditions, the sums of minimum daily air temperatures in the autumn-winter period preceding the rootage of rootstock cuttings were taken into account. The correlation between three stages of rhizogenesis was determined by the method of correlation and regression analysis.

\section{Results and Discussion}

In terms of the grape plant's biology, the process of root formation begins in the xylem layers near the wood rays and the root base makes its way through the tissues of the phloema and periderm and goes outward in the form of white tubercles. Roots' formation, growth and increase in their number happens further from this root base. The course of the initial stage is virtually impossible to be visually evaluated, so it will not be taken into account. Thus, the process of grapes' roots formation can be conditionally divided into three consecutive stages: the appearance of root base, roots formation from the root base and an increase in the number of roots. 
At the first stage of root formation with vegetative grapes' reproduction, one of the indicators of rhizogenesis activity is the intensity of root base formation (Table 2). On average, statistically reliable efficacy of Heteroauxin, MPC-1 and MPC-2 was observed in all studied concentrations over four years of research. Data for four research years demonstrate that the intensity of root base formation on cuttings in different years was not the same; the values difference in the control option was from $40.0 \%$ in 2018 to $73.3 \%$ in 2017 , which in turn corresponds to a significant variation degree $(C v=24.3 \%)$.

Table 2. Influence of stimulants on the number of cuttings with root base of Berlandieri x Riparia Kober 5 BB rootstock grape variety, 2017-2020, \%.

\begin{tabular}{|l|c|c|c|c|c|c|}
\hline \multicolumn{1}{|c|}{ Option } & 2017 & 2018 & 2019 & 2020 & $\begin{array}{c}\text { Average } \\
\text { value }\end{array}$ & $\begin{array}{c}\mathrm{Cv}, \\
\%\end{array}$ \\
\hline $\begin{array}{l}\text { 1. Control (no } \\
\text { treatment) }\end{array}$ & $73.3 \pm 5.3$ & $40.0 \pm 0.7$ & $60.0 \pm 2.5$ & $68.3 \pm 0.7$ & $\begin{array}{c}60.4 \pm \\
8.5\end{array}$ & 24.3 \\
\hline $\begin{array}{l}\text { 2. Heteroauxin } 0.02 \% \\
\text { solution }\end{array}$ & $100.0 \pm 0.0$ & $80.0 \pm 2.5$ & $80.0 \pm 2.9$ & $96.7 \pm 1.5$ & $\begin{array}{c}89.2 \pm \\
6.2\end{array}$ & 12.0 \\
\hline $\begin{array}{l}\text { 3. MPC-1 base } \\
\text { solution }\end{array}$ & $84.6 \pm 3.9$ & $90.0 \pm 1.5$ & $83.3 \pm 1.1$ & $63.3 \pm 2.0$ & $\begin{array}{c}80.3 \pm \\
6.8\end{array}$ & 14.6 \\
\hline 4. MPC-1 diluted 1:10 & $87.9 \pm 1.9$ & $80.0 \pm 1.6$ & $80.0 \pm 2.5$ & $83.3 \pm 1.5$ & $\begin{array}{c}82.8 \pm \\
2.2\end{array}$ & 4.5 \\
\hline $\begin{array}{l}\text { 5. MPC-1 diluted } \\
\text { 1:100 }\end{array}$ & $93.3 \pm 2.5$ & $65.0 \pm 2.3$ & $80.0 \pm 1.4$ & $73.3 \pm 0.4$ & $\begin{array}{c}77.9 \pm \\
6.9\end{array}$ & 15.4 \\
\hline $\begin{array}{l}\text { 6. MPC-2 base } \\
\text { solution }\end{array}$ & $76.7 \pm 3.6$ & $40.0 \pm 0.8$ & $86.7 \pm 0.4$ & $83.3 \pm 2.9$ & $\begin{array}{c}71.7 \pm \\
12.4\end{array}$ & 30.0 \\
\hline 7. MPC-2 diluted 1:10 & $90.0 \pm 2.9$ & $80.0 \pm 2.3$ & $90.0 \pm 1.2$ & $93.3 \pm 1.1$ & $\begin{array}{c}88.3 \pm \\
3.3\end{array}$ & 6.5 \\
\hline $\begin{array}{l}\text { 8. MPC-2 diluted } \\
\text { 1:100 }\end{array}$ & $80.0 \pm 1.5$ & $80.0 \pm 2.9$ & $76.7 \pm 2.3$ & $93.3 \pm 2.9$ & $\begin{array}{c}82.5 \pm \\
4.3\end{array}$ & 8.9 \\
\hline NSR 05 & 12.5 & 8.7 & 9.4 & 8.8 & 9.3 & - \\
\hline
\end{tabular}

Thus, it can be concluded that the natural ability of grape cuttings to form the root base will largely depend on the conditions that have developed in the year preceding to rooting, as confirmed by our early studies $[18,22]$. The effect of lower temperatures in the autumnwinter period on the parent vine accelerates the exit of rootstock grape from the biological rest state, which is manifested in earlier hibernating buds' shooting. In this case, the rooting period is lengthened. In the vast majority of options, artificial stimulation of root formation not only contributed to an increase in the proportion of cuttings with root base, but also leveled the influence of the year's conditions, which was manifested in reduction of the variation coefficients' values. This fact is also confirmed by the results of two-factor dispersion analysis, which showed that the "stimulant" factor influence share determines the number of cuttings with root base by $22.9 \%$, the factor "condition of the year" determines this indicator by $5.5 \%$, and the share of interaction between these two factors is $58.6 \%$ with a significant difference in all options (Table 3 ).

Table 3. Results of two-factor dispersion analysis of cuttings with root base share variability depending on the influence of the year and stimulants.

\begin{tabular}{|l|c|c|c|c|c|}
\hline \multicolumn{1}{|c|}{ Factors } & $\begin{array}{c}\text { Factor } \\
\text { share }\end{array}$ & F fact & $\begin{array}{c}\text { F } \\
5 \%\end{array}$ & $\begin{array}{c}\text { HCP } \\
5 \%\end{array}$ & $\begin{array}{c}\text { Differences } \\
\text { are } \\
\text { substantial }\end{array}$ \\
\hline Factor A (stimulant) & 22.9 & 21.10 & 1.72 & 4.63 & $*$ \\
\hline Factor B (year) & 5.5 & 13.58 & 1.74 & 3.09 & $*$ \\
\hline AB interaction & 58.6 & 18.01 & 1.76 & 3.09 & $*$ \\
\hline Random variability & 13.0 & & & & \\
\hline \multicolumn{6}{|c|}{ To assess the materiality of particular differences, NSR $=9.26$} \\
\hline
\end{tabular}


Analyzing the second root formation stage in cuttings of Berlandieri x Riparia Kober $5 \mathrm{BB}$ rootstock variety - namely the period of root formation from root base - it can be concluded that growth of cuttings with roots without treatment with stimulants averaged to $50.7 \%$ over four years (Table 4). At the same time, there is a significant variation of this trait by year $(C v=42.4 \%)$. Treatment with Heteroauxin contributed to the increase of cuttings with roots to $74.0 \%$. When using the microbial preparations as a growth stimulant, namely MPC-1 and MPC-2 at 1:10 concentrations, the observed effect was at the level of Heteroauxin. However, there were no significant differences between these concentrations $\left(\mathrm{NSR}_{05}=14.7\right)$.

Table 4. Influence of stimulants on the number of cuttings with roots of Berlandieri x Riparia Kober 5 BB rootstock grape variety, 2017-2020,\%.

\begin{tabular}{|l|c|c|c|c|c|c|}
\hline \multicolumn{1}{|c|}{ Option } & 2017 & 2018 & 2019 & 2020 & $\begin{array}{c}\text { Average } \\
\text { value }\end{array}$ & $\begin{array}{c}\text { Cv, } \\
\%\end{array}$ \\
\hline 1. Control (no treatment) & $66.7 \pm 8.0$ & $20.0 \pm 6.7$ & $55.6 \pm 3.4$ & $60.3 \pm 2.9$ & $50.7 \pm 12.1$ & 42.4 \\
\hline 2. Heteroauxin 0.02\% solution & $90.0 \pm 7.3$ & $50.0 \pm 9.3$ & $69.2 \pm 4.3$ & $86.7 \pm 1.6$ & $74.0 \pm 12.6$ & 31.5 \\
\hline 3. MPC-1 base solution & $73.1 \pm 3.6$ & $70.0 \pm 5.7$ & $70.0 \pm 4.3$ & $36.7 \pm 4.1$ & $62.5 \pm 9.9$ & 27.6 \\
\hline 4. MPC-1 diluted 1:10 & $87.9 \pm 9.8$ & $40.0 \pm 2.0$ & $73.3 \pm 1.6$ & $76.7 \pm 5.1$ & $69.5 \pm 11.9$ & 29.7 \\
\hline 5. MPC-1 diluted 1:100 & $86.7 \pm 12.0$ & $40.0 \pm 8.3$ & $74.4 \pm 8.8$ & $56.7 \pm 4.3$ & $64.5 \pm 11.8$ & 31.7 \\
\hline 6. MPC-2 base solution & $66.7 \pm 7.0$ & $25.0 \pm 2.2$ & $71.1 \pm 4.1$ & $63.3 \pm 3.6$ & $56.5 \pm 12.3$ & 48.5 \\
\hline 7. MPC-2 diluted 1:10 & $83.3 \pm 2.9$ & $60.0 \pm 9.4$ & $77.8 \pm 4.6$ & $76.7 \pm 2.9$ & $74.5 \pm 5.8$ & 13.5 \\
\hline 8. MPC-2 diluted 1:100 & $60.0 \pm 8.3$ & $50.0 \pm 7.4$ & $52.2 \pm 5.7$ & $83.3 \pm 2.9$ & $61.4 \pm 8.8$ & 24.8 \\
\hline NSR $_{05}$ & 15.6 & 5.4 & 12.5 & 10.2 & 14.7 & - \\
\hline
\end{tabular}

Comparing the data of the first two rhizogenesis stages, it can be concluded that despite the use of various stimulants, some cuttings with root base never formed roots afterwards. Moreover, in the control option without stimulation, this indicator on average for four years reached 9.7\%; under the action of the studied microbial complexes MPC-1 and MPC-2 in 1:10 concentrations, this indicator amounted to $13.3 \%$ and $13.8 \%$ respectively, and the use of traditional Heteroauxin increased this value to $15.2 \%$. Proceeding from this, it can be concluded that the use of these biopreparations' concentrations contributes to a more rational energy use of carbohydrates stored in the vine, which is spent on the formation of root tubercles and a more complete opening of the rhizogenesis potential when compared to other stimulation methods.

Results of the two-factor dispersion analysis of the cuttings with roots share variability determined the increase in the influence of the "stimulant" factor to $34.5 \%$ in comparison with the previous root formation stage; the influence of the year's conditions also increased to $6.8 \%$, and the share of these factors' interaction decreased to $46.5 \%$ with a significant difference in all options (Table 5).

Table 5. Results of the two-factor dispersion analysis of the cuttings with roots share variability depending on the influence of the year and stimulants.

\begin{tabular}{|l|c|c|c|c|c|}
\hline \multicolumn{1}{|c|}{ Factors } & $\begin{array}{c}\text { Factor } \\
\text { share }\end{array}$ & F fact & F 5 \% & $\begin{array}{c}\text { HCP } \\
5 \%\end{array}$ & $\begin{array}{c}\text { Differences } \\
\text { are } \\
\text { substantial }\end{array}$ \\
\hline Factor A (stimulant) & 34.5 & 24.93 & 1.72 & 7.33 & $*$ \\
\hline Factor B (year) & 6.8 & 13.01 & 1.74 & 4.89 & $*$ \\
\hline AB interaction & 46.5 & 11.19 & 1.76 & 4.89 & $*$ \\
\hline Random variability & 12.2 & & & \\
\hline \multicolumn{7}{|l|}{ To assess the materiality of particular differences, NSR $=14.66$} \\
\hline
\end{tabular}

One of the criteria determining the grade of planting material is the presence of at least 3 main roots. The analysis showed that growth regulators, regardless of their origin, had a 
significant impact on the root system formation (Table 6). Heteroauxin and the studied microbial complexes MPC-1 and MPC-2 in 1:10 dilution were on average effective in this indicator relative to the control option over all years of research. It is worth noting that at this stage of root formation, there is a significant variation in years in all experimental options.

Table 6. Influence of stimulants on the number of cuttings with 3 or more roots of Berlandieri $x$ Riparia Kober 5 BB rootstock grape variety, 2017-2020,\%.

\begin{tabular}{|l|c|c|c|c|c|c|}
\hline \multicolumn{1}{|c|}{ Option } & 2017 & 2018 & 2019 & 2020 & $\begin{array}{c}\text { Average } \\
\text { value }\end{array}$ & $\begin{array}{c}\mathrm{Cv}, \\
\%\end{array}$ \\
\hline $\begin{array}{l}\text { 1. Control (no } \\
\text { treatment) }\end{array}$ & $60.0 \pm 4.6$ & $20.0 \pm 3.5$ & $\begin{array}{c}46.7 \pm 4 . \\
3\end{array}$ & $43.3 \pm 0.8$ & $\begin{array}{c}42.5 \pm \\
8.3\end{array}$ & 33.0 \\
\hline $\begin{array}{l}\text { 2. Heteroauxin 0.02\% } \\
\text { solution }\end{array}$ & $86.7 \pm 11.5$ & $35.0 \pm 5.7$ & $\begin{array}{c}63.3 \pm 7 . \\
3\end{array}$ & $56.7 \pm 5.7$ & $\begin{array}{c}62.9 \pm \\
10.1\end{array}$ & 47.1 \\
\hline 3. MPC-1 base solution & $61.5 \pm 5.0$ & $50.0 \pm 5.1$ & $\begin{array}{c}50.0 \pm 4 . \\
3\end{array}$ & $26.7 \pm 1.6$ & $\begin{array}{c}47.1 \pm \\
8.4\end{array}$ & 31.1 \\
\hline 4. MPC-1 diluted 1:10 & $72.7 \pm 8.5$ & $30.0 \pm 4.2$ & $\begin{array}{c}70.0 \pm 1 . \\
6\end{array}$ & $76.7 \pm 3.6$ & $\begin{array}{c}62.4 \pm \\
12.6\end{array}$ & 34.9 \\
\hline 5. MPC-1 diluted 1:100 & $83.3 \pm 5.0$ & $25.0 \pm 2.9$ & $\begin{array}{c}53.3 \pm 2 . \\
2\end{array}$ & $43.3 \pm 2.9$ & $\begin{array}{c}51.2 \pm \\
14.1\end{array}$ & 47.6 \\
\hline 6. MPC-2 base solution & $53.3 \pm 7.1$ & $15.0 \pm 2.2$ & $\begin{array}{c}20.0 \pm 3 . \\
7\end{array}$ & $56.7 \pm 2.9$ & $\begin{array}{c}36.3 \pm \\
12.6\end{array}$ & 60.1 \\
\hline 7. MPC-2 diluted 1:10 & $70.0 \pm 5.7$ & $45.0 \pm 5.7$ & $\begin{array}{c}50.0 \pm 6 . \\
5\end{array}$ & $76.7 \pm 0.8$ & $\begin{array}{c}60.4 \pm \\
8.8\end{array}$ & 25.3 \\
\hline 8. MPC-2 diluted 1:100 & $50.0 \pm 9.4$ & $25.0 \pm 6.7$ & $\begin{array}{c}43.3 \pm 3 . \\
6\end{array}$ & $83.3 \pm 4.6$ & $\begin{array}{c}50.4 \pm \\
14.1\end{array}$ & 48.3 \\
\hline NSR05 & 18.2 & 10.7 & 10.3 & 7.3 & 11.5 & - \\
\hline
\end{tabular}

Results of two-factor dispersion analysis of the cuttings with 3 or more roots share variability determined the influence of the "stimulant" factor at the level of $33.6 \%$, the effect of the year conditions - at $9.3 \%$ level, and the share of these factors' interaction $50.2 \%$ with a significant difference in all options (Table 7).

Table 7. Results of two-factor dispersion analysis of the cuttings with 3 or more roots share variability depending on the influence of the year and stimulants.

\begin{tabular}{|l|c|c|c|c|c|}
\hline \multicolumn{1}{|c|}{ Factors } & $\begin{array}{c}\text { Factor } \\
\text { share }\end{array}$ & $\begin{array}{c}\mathrm{F} \\
\text { fact }\end{array}$ & $\begin{array}{c}\mathrm{F} \\
5 \%\end{array}$ & $\begin{array}{c}\mathrm{HCP} \\
5 \%\end{array}$ & $\begin{array}{c}\text { Differences } \\
\text { are } \\
\text { substantial }\end{array}$ \\
\hline Factor A (stimulant) & 33.6 & 45.64 & 1.72 & 5.77 & $*$ \\
\hline Factor B (year) & 9.3 & 33.54 & 1.74 & 3.85 & $*$ \\
\hline AB interaction & 50.2 & 22.71 & 1.76 & 3.85 & $*$ \\
\hline Random variability & 6.9 & \multicolumn{5}{|c|}{} & \\
\hline \multicolumn{6}{|l|}{ To assess the materiality of particular differences, NSR $=11.54$} \\
\hline
\end{tabular}

Results of two-factor dispersion analyses of all three root formation stages allows to conclude that the "stimulant" factor influence increases from the first stage to subsequent ones; the same trend is also observed relative to the "condition of the year" factor, and on the contrary, the influence of random variability decreases with each new rhizogenesis stage.

As a result of both single-factor and two-factor dispersion analyses, the obtained indicators of the least significant difference confirm the conclusions about the effectiveness of the aqueous suspensions use of new microbial complexes MPC-1 and MPC-2 in 1:10 dilution as root stimulants on Berlandieri x Riparia Kober 5BB rootstock grape variety. 
The formulated conclusions are confirmed by the method of correlation relations' identification. For effective root stimulants use, it is necessary to determine the rhizogenic activity potential of grape rootstocks at separate root system formation stages of the future planting material.

The correlation between three rhizogenesis stages of the grape rootstock (Table 8) was determined by the method of correlation and regression analysis.

The relationship between the first and second root formation stages, root base and root formation describes the relationship between the studied traits as direct; the correllation ratio as per the Chaddock scale is very high. The increase intensity in the number of cuttings with roots of $83.2 \%$ depends on the root base formation intensity.

The relationship between the second and third root formation stages, the formation of roots and the formation of 3 or more roots also describes the relationship between the studied traits as direct, and the correllation ratio as per the Chaddock scale is very high. The intensity of increasing the number of cuttings with 3 or more roots by $82.2 \%$ depends on the root formation intensity.

The relationship between the second and third root formation stages, the formation of roots and the formation of 3 or more roots describes the relationship between the studied traits as direct, and the correllation ratio as per the Chaddock scale is high. The intensity of increasing the number of cuttings with 3 or more roots by $60.3 \%$ depends on the root base formation intensity.

This analysis demonstrated the fact that there is a very high influence of the studied traits (the number of cuttings with root base, with roots and 3 or more roots) on each other at adjacent root formation stages. At distant stages, the relationship between traits weakens. On this basis, with the comparative stimulants' characteristics, a smaller decrease in the relationship between root formation traits at distant rhizogenesis stages will indicate more prolonged stimulation effect.

Table 8. Results of correlation and regression analysis of the relationship between rhizogenesis stages.

\begin{tabular}{|l|c|c|c|}
\hline \multicolumn{1}{|c|}{ Stages of root formation } & $\begin{array}{c}\text { Root base } \\
\text { formation }\end{array}$ & $\begin{array}{c}\text { Roots formation } \\
\text { from root base }\end{array}$ & $\begin{array}{c}\text { Formation of 3 or } \\
\text { more roots }\end{array}$ \\
\hline & Correlation coefficient $(\mathrm{r})$ & 0.776 \\
\hline Root base formation & $\mathrm{x}$ & 0.912 & 0.907 \\
\hline $\begin{array}{l}\text { Roots formation from root } \\
\text { base }\end{array}$ & 0.912 & $\mathrm{x}$ & $\mathrm{x}$ \\
\hline Formation of 3 or more roots & 0.776 & 0.907 & $\mathrm{y}=-4.382+0.715 \mathrm{x}$ \\
\hline \multicolumn{4}{|c|}{ Paired linear regression equation } \\
\hline Root base formation & $\mathrm{x}$ & $\mathrm{y}=7.152+0.727 \mathrm{x}$ & $\mathrm{y}=-15.470+$ \\
\hline $\begin{array}{l}\text { Roots formation from root } \\
\text { base }\end{array}$ & $\mathrm{y}=7.152+0.727 \mathrm{x}$ & $\mathrm{x}$ & $\mathrm{x}$ \\
\hline $\begin{array}{l}\text { Formation of 3 or more roots } \\
\mathrm{y}=-4.382+ \\
0.715 \mathrm{x}\end{array}$ & $\mathrm{y}=-15.470+$ \\
\hline & $\mathrm{Determination} \mathrm{coefficient}\left(\mathrm{r}^{2}\right)$ & $047 \mathrm{x}$ \\
\hline Root base formation & $\mathrm{x}$ & 0.832 & 0.602 \\
\hline $\begin{array}{l}\text { Roots formation from root } \\
\text { base }\end{array}$ & 0.832 & $\mathrm{x}$ & $\mathrm{x}$ \\
\hline Formation of 3 or more roots & 0.602 & 0.823 & 0.823 \\
\hline
\end{tabular}

The analysis of the obtained data allows to distinguish MPC-1 and MPC-2 in 1:10 dilution as the most optimal concentrations of the investigated microbial preparations' complexes and to draw a conclusion about the effectiveness of these microbial complexes as stimulants of root formation for Berlandieri x Riparia Kober 5BB rootstock grape variety cuttings. It is worth noting that the effectiveness of these complexes is manifested 
throughout all rhizogenesis stages from the root base formation to the formation of 3 or more roots.

In all experimental options, there was a decrease in the stimulation intensity at each of the subsequent root formation stages. The use of traditional root stimulant Heteroauxin contributes to the increase in the root base relative to Control on average for four years by $28.8 \%$; at the next stage (roots formation from the root base), the effect is already $23.3 \%$, and at the stage of the number of roots exceeding 3 the effect is $20.4 \%$; the use of MPC-1 and MPC-2 in 1:10 dilution increases the number of cuttings with root base by $22.4 \%$ and $27.9 \%$ respectively, therefore at the stage of root formation from the root base - by $18.8 \%$ and $23.8 \%$ respectively, and at the stage of increasing the number of roots - by $19.9 \%$ and $17.9 \%$ respectively. Thus, the investigated microbial preparations' complexes in 1:10 dilution have a stimulating effect at all stages of root formation comparable with the traditional chemical analog.

The research of other authors also notes the positive influence of biopreparation complexes based on active strains of nitrogen-assimilating and phosphate-mobilizing microorganisms on young plants' growth and development. In the studies of Klimenko O.E. et al. $[6,9,10]$, the positive microbial complexes' effect on the establishment, growth and development of cherry, peach, cherry-plum and apricot seedlings in fruit nursery was noted, including by increasing the number and root length. In experiments on the stone fruit crops' rootstock and cherry seedlings, Kuznetsova A.P. et al. note the stable effective impact of microbial preparations on the quality of planting material [2]. In the research in the grape nursery, Yurchenko E.G. and Politova Z.S. note that the use of biopreparations contributes to better adaptation of plants to stress factors due to better root system development of grape seedlings $[1,16,17]$.

\section{Conclusion}

Studies have shown that the natural ability of grape cuttings to form root base, roots and increase their numbers is largely dependent on the conditions of the year preceding rooting. The effect of the sum of low temperatures during the winter period on the mother vines accelerates the exit of rootstock grape varieties from the state of biological rest, which is manifested in earlier hibernating buds' shooting. In this case, the rooting period is lengthened. Artificial stimulation not only contributes to an increase in root formation indicators, but also negates the influence of the year's conditions.

The use of microbial complexes reduces the number of cuttings with root base without subsequent root formation up to $13.3-13.8 \%$ in comparison with Heteroauxin $(15.2 \%)$, which indicates a more rational energy use of carbohydrates stored in the vine.

The optimal breeding range of new microbial complexes based on multifunctional strains of microorganisms MPC-1 and MPC-2 is 1:10. This concentration most contributes to the rhizogenic activity potential increase of the Berlandieri x Riparia Kober 5 BB rootstock grape variety at all root formation stages and in its efficacy approaches the action of the traditional chemical stimulant Heteroauxin. This, in turn, is the basis for future studies aimed at finding the optimal concentration in the given range.

The observed microbial complexes' stimulating effect on root formation of rootstock grape variety is consistent with research data on other crops and contributes to the expansion of the stimulants' use scope based on microbial synthesis, and the increase in the volume of their use will reduce the share of chemicals in the production of high-quality grafted grape planting material. 


\section{References}

1. Z.S Politova, E.G. Yurchenko, Proc. of the All-Russ. Conf. "Scientific support of the agro-industrial complex", 478 (2016)

2. A.P. Kuznetsova, S.N. Shcheglov, A.I. Drygina, M.Yu. Gutnichenko, Collection of scientific works of the State Nikitinskiy botanical garden, 144-2, (2017)

3. T.N. Melnichuk, T.Yu. Parkhomenko, A.A. Loloiko, I.A. Kameneva, Chemistry and biology: scientif. e-journ, 7 (2014), http://7universum.com/

4. P. Calvo, L. Nelson, J.W. Kloepper, Soil, 383, 3 (2014)

5. O.E. Klimenko, N.I. Klimenko, A.R. Akchurin, N.N. Klimenko, Problems of agrochemistry and ecology, 4, 23 (2016)

6. O.E. Klimenko, N.I. Klimenko, I.A. Kamenev, Proceedings of the intern.conf. "Genetic integration of prokaryotes and eukaryotes: fundamental research and modern agrotechnologies", 79 (2015)

7. I.V. Maksimov, S.V. Veselova, T.V. Nuzhnaya, E.R. Sarvarova, R. M. Khairullin, Plant Physiology, 6, 763 (2015)

8. L.A. Chaikovskaya, M.I. Baraeskaya, Coll.: Agricultural microbiology, 9, 68 (2009)

9. O.E. Klimenko, Scientific works of the Southern branch of the National University of Bioresources and Nature Management of Ukraine, 161, 96 (2014)

10. O.E. Klimenko. N.I. Klimenko, L.E. Kartyzhova, Z.M. Aleschenkova, Scientific works of the Southern branch of the National University of Bioresources and Nature Management of Ukraine, 154, 175 (2013)

11. A.P. Kuznetsova, A.I. Drygina, S.I. Gridnev, Scientific works of the North-Caucasian Federal Scientific Center of Horticulture, Viticulture and Wine-making, 14, 131 (2018)

12. N.N. Klimenko, Proceeding of the intern.conf. "Genetic integration of prokaryotes and eukaryotes: fundamental research and modern agrotechnologies", 80 (2015)

13. L.A. Tchaikovskaya, N.N. Klimenko, Agrarian Bulletin of Urals, 3(145), 72 (2016)

14. Z.S. Politova, Almanac of World Science, 1, 38 (2016)

15. P. P. Radchevsky, Influence of biologically active substances on regeneration properties of grape cuttings, yield and quality of seedlings, 275 (2017)

16. E.G. Yurchenko, A.A. Lukianova, V.N. Puchkov, Scientific Life, 7, 1115 (2019)

17. E.G. Yurchenko, Z.S. Politova, Horticulture and Viticulture, 4, 21 (2016)

18. V.I. Ivanchenko, A.I. Yakubovskaya, A.Yu. Zotikov, Viticulture and Winemaking, 48, 28 (2019)

19. Y. Ding, J. Wang, Y. Liu, S. Chen. J. Appl. Microbiol, 99, 1271 (2005)

20. R.M. Shivani, V. Bahadur, 67 (2019)

21. GOST R 53050-2008 "Material for grape reproduction (cuttings, shoots), Technical conditions" (Moscow) (2009)

22. V.I. Ivanchenko, O.G. Zameta, D.V. Potanin, A.Yu. Zotikov, Proceedings of Tavrida agricultural science, 15(178), 16 (2018) 